Perspectiva Geográfica

ISSN 0123-3769

Vol. 15/2010; pp. 85-112

\title{
Transformación urbana de la ciudad de Bogotá, 1990 2010: efecto espacial de la liberalización del comercio
}

Urban transformation of the Bogotá city, 1990 2010: spatial effect of the liberalization of commerce

Jorge Alessandri Romero Novoa*

\section{Resumen}

Se analiza en el artículo la transformación urbana de Bogotá en los últimos 20 años, adelantada en el marco de los procesos de globalización y liberalización del comercio. Los cambios se examinan, entonces, a partir de la relación existente entre comercio, población y suelo urbano, desde la cual se genera el análisis del aumento en el PIB por sectores, el crecimiento poblacional y las variaciones del uso del suelo, como principales evidencias de evolución económica y urbana de la ciudad. El documento contiene una descripción de los fenómenos producidos en el suelo urbano.

Palabras clave: Ciudad, Espacio glocal, Espacio incontinenti, Estructura urbana, Expansión, Fragmentación, Globalización, Liberalización del comercio, Morfología urbana.

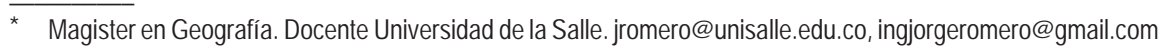




\section{Abstract}

This article analyses the urban transformation of Bogotá in the past 20 years within the framework of globalization and commerce liberalization processes. The changes are examined, then, from the relationship between commerce, population and urban soil; from which the analysis of the increase in GDP is generated, population growth and changes in the urban uses of soil, as major evidence of urban and economic development of the city. The document contains a description of changes produced in urban soil.

Key words: City, Expansion, Glocal space, Incontinenti Space, Fragmentation, Globalization, Liberalization of Commerce, Re densification, Urban Morphology.

86 Jorge Alessandri Romero Novoa 


\section{Introducción}

El tema de este artículo surge del interés por entender el alcance urbano de la globalización en un país como Colombia; en esencia, tiene por objetivo describir en qué sentido se ha transformado Bogotá, desde los años noventa y hasta la actualidad, con la liberalización del comercio. De esta manera, se manejó un escenario dirigido a un espacio concreto, la ciudad, y enmarcado en un periodo específico, finales del siglo $\mathrm{xx} \mathrm{y}$ comienzos del nuevo milenio. Tomando como base datos económicos, poblacionales y del suelo urbano, el artículo explora los cambios de la ciudad observados durante los últimos veinte años.

El fenómeno de la liberalización comercial ha producido en las ciudades una reacción cambiante de sus sectores económicos, que se traduce en alteraciones del espacio urbano. La afluencia de recursos, capitales, productos, servicios e información define nuevas relaciones del mercado local con el global, e inversamente, y los procesos de desindustrialización, sustitución comercial y de servicios, las variaciones poblacionales y los cambios de uso del suelo son las principales evidencias de transformación urbana de Bogotá.

El documento se organiza en cuatro apartados. El primero hace referencia a la relación de los cambios económicos de Bogotá (variaciones de la participación en el PIB nacional, las exportaciones e importaciones) con la evolución socioespacial del plano urbano, definida en dos momentos económicos que coinciden con la evolución de la globalización de los mercados mundiales. El segundo relaciona las variaciones de los tamaños poblacionales y su incidencia en la evolución de la ciudad, identificando áreas urbanas y suelo periurbano que soportan los incrementos más importantes. El tercero presenta un análisis de la desindustrialización y la terciarización de las actividades productivas de la capital, como indicadores de cambio económico y urbano, señalando las zonas en donde se concentran dichos cambios. Un último aparte define de manera concreta los principales fenómenos indicadores de la transformación urbana de la ciudad.

\section{Globalización y liberalización del comercio en Bogotá}

En el siglo xx, el proceso de globalización introdujo cambios en las economías de los países latinoamericanos (De Mattos, 2002); algunos reflejados, por ejemplo, en el cambio entre sectores y actividades productivas: de industria a comercio o de comercio a servicios; uno de estos tuvo que ver con la liberalización del comercio, la cual pretendía aumentar la movilidad de los capitales y disminuir las restricciones comerciales entre las ciudades, de tal forma que se produjeran políticas aperturistas que facilitaran que los mercados internacionales y transnacionales se instalaran sobre un conjunto de localidades esencialmente tradicionales y con un modernismo en construcción. 
Para Colombia y sus principales ciudades (Bogotá, Medellín, Cali, Barranquilla y Bucaramanga), la llegada del anterior contexto se dio a finales de los años ochenta y comienzos de los noventa; entre 1990 y 1997, el nuevo modelo económico se enmarcó en la implantación de políticas comerciales aperturistas y se insertó oficialmente en la tercera etapa de la globalización ${ }^{1}$, con un antecedente normativo, como lo fue la Ley 9 de 1989 , o Ley de Reforma Urbana. En 1997 se promulgó la Ley 388, o Ley de Desarrollo Territorial, a partir de la cual se establecían y reglamentaban los usos y las formas de ocupación del suelo; a lo cual se suman las variaciones demográficas enmarcadas en el tercer ciclo de compactación urbana para finales de 1999 y comienzos del 2000 (Pérez, 1999).

\subsection{Bogotá: una ciudad con una economía comercial y de servicios (1991-2000)}

Con las transformaciones de los últimos años, Bogotá [...] parece haber asumido la necesidad de encontrarse a sí misma, potenciar y desarrollar su papel en el nuevo contexto de las ciudades. Un proceso reflexivo que ha tenido como punto de partida la búsqueda y construcción de una o varias identidades, el aprendizaje de la convivencia y el descubrimiento del espacio público... (Duque, 2008: 1).

Elementos como su localización geográfica en el centro del país, su entorno productivo rural, su capacidad de liderazgo comercial, su funcionalidad institucional y su acopio de capitales foráneos configuraron cambios en la espacialidad de su suelo urbano; de tal manera que la ciudad trasciende su espacio urbano y se traslapa con municipalidades del entorno, consolidando desde los años setenta su primacía como ciudad (Moncayo, 2007).

En la década de 1991 al 2000, la liberalización del comercio incluye efectos sobre la producción de bienes y servicios, las exportaciones e importaciones de Bogotá (CID, 2005). El aumento en la movilidad de capitales, la disminución de restricciones, la sustitución de productos y la interrelación con otras ciudades son sus principales dinámicas. Estas variaciones son las que particularmente inciden en la producción económica de Bogotá y en su participación nacional.

La transición económica de Bogotá, de un sistema de desarrollo industrial a otro de terciarización de las actividades

Cuervo hace referencia a la periodización de la globalización en tres grandes etapas: “... Los años 1970... una primera época de turbulencia e incertidumbre donde el desconcierto y la experimentación de respuestas priman. Durante esta década no debe hablarse aún de la consolidación de nuevas reglas del juego. Los años $80 . .$. las bases de las nuevas reglas del juego como resultado del cambio drástico en las condiciones de manejo nacional e internacional de los asuntos financieros, monetarios y fiscales en los países desarrollados y en sus foros de concertación de políticas. En los años 90 se consolidan las reglas del juego gestadas en la década anterior y aparece por primera vez en estos últimos 30 años un crecimiento simultáneo de las economías latinoamericanas y desarrolladas del norte..."(1999: 3). 
económicas, y, en el comienzo de siglo (con mayor fuerza), la inserción en mercados y procesos internacionales de globalización (Montoya, 2004) son consecuecia de la implantación a comienzos de los años noventa de las políticas comerciales aperturistas. Algunas de las cifras más importantes que describen la evolución económica de la capital colombiana parten del estudio realizado por el Centro de Investigaciones para el Desarrollo (CID, 2005), en el cual, al analizar la balanza comercial relativa, la ciudad en sí misma es más importadora que el país como un todo; esto se puede evidenciar, por ejemplo, en el total nacional: la participación en las importaciones fue de $28,05 \%$ y en las exportaciones, solo del 2,05\%; valores que aumentan considerablemente en relación con Bogotá-región ${ }^{2}$, siendo del $53,9 \%$ en las importaciones, y las exportaciones solo representan un 29,3\% (CID, 2005: 4-5). El PIB por sectores de la capital en este periodo tuvo un cambio productivo que se concentró en tres actividades económicas: industria, comercio y servicios (Figura 1).

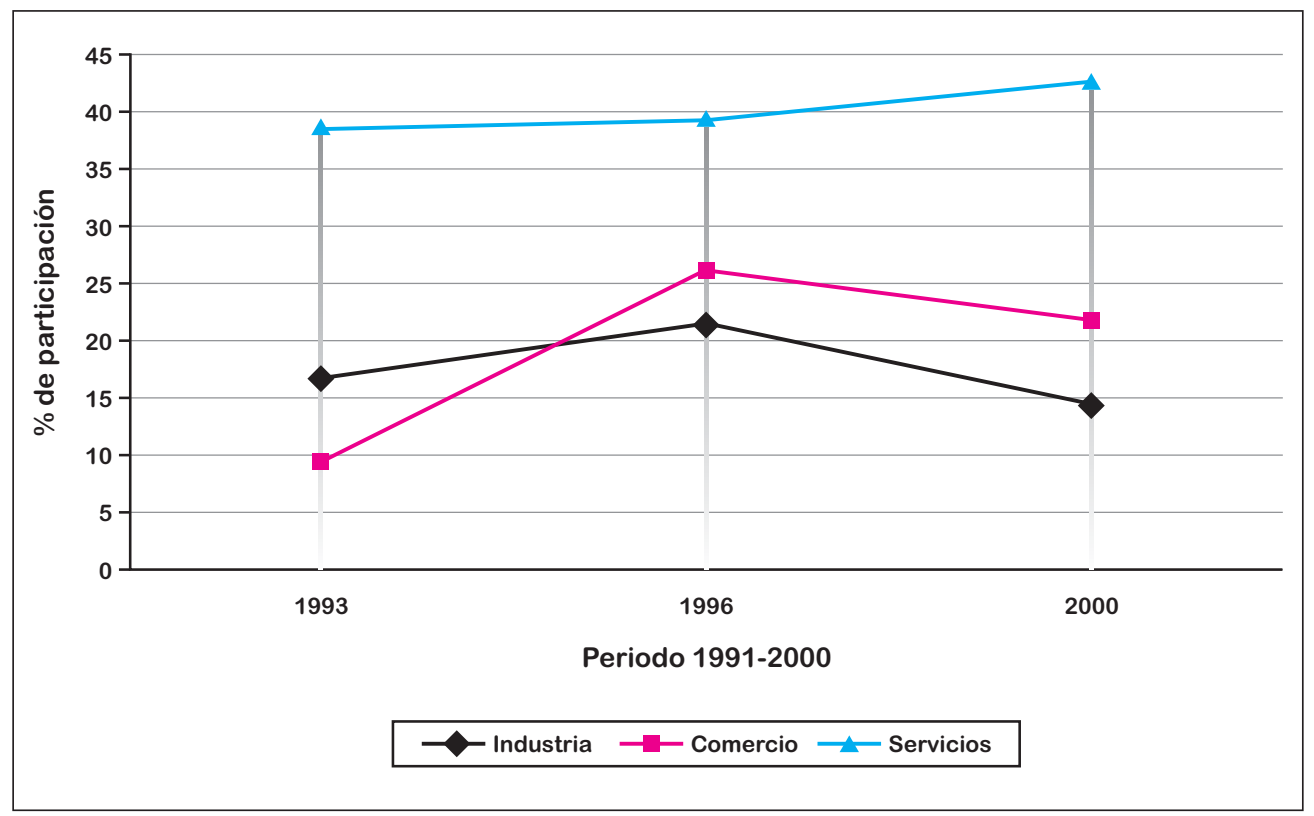

Figura 1. Cambios en el PIB por sectores de Bogotá. 1991-2000

Fuente: elaboración propia a partir de cifras de la Secretaría Distrital de Hacienda (SDH). 2010.

2 Es un concepto económico espacial de diferentes acepciones y muy polisémico, sin un debate cerrado, entendido aquí de manera funcional, dentro del cual la ciudad es el epicentro y las demás entidades territoriales conforman una región integrada por actividades socioeconómicas. Sin embargo, la investigación no pretende su discusión teórica, solamente usa los datos relacionados con el PIB, la participación productiva y el nivel de exportaciones-importaciones que tiene para su comparación con la ciudad y la nación. No existe un objetivo distinto en su utilización. 
Esta relación entre las cifras de la ciudad en el total nacional es de 13 a 1, y en el total Bogotá-región es de casi 2 a 1 , y permite comprender que para este periodo 1990-2001 (en ese momento una economía abierta) la sustitución parcial de la producción interna por manufacturados importados da cabida al comercio y a la disposición de servicios sociales, personales y empresariales como actividades locales y con alcances urbano-regionales ${ }^{3}$. Para la época, el valor de la producción representa el $81,5 \%$ de la producción de la región, teniendo en cuenta que la producción de Bogotá era más para el consumo interno.

Ahora, al analizar el índice de la balanza comercial relativa de la ciudad $-0,87 \%$ este se encuentra por encima del promedio nacional -0,5\%-, lo que indicó que Bogotá es una ciudad importadora frente a la región y al país como un todo, pues su producción es más para el consumo interno, así como la diversificación de los mercados y la relativa disminución de la oferta exportable. El coeficiente de penetración de importaciones es del 14\% del consumo aparente, mientras que la tasa exportadora es del $1 \%$ del total de la producción, una relación relevante para comprender la sustitución comercial y su posterior incidencia en los mercados locales. Sin embargo, la participación de la producción de Bogotá en el total nacional fue del $20,6 \%$, una cifra que ciertamente quintuplica la del departamento de Cundinamarca y justifica la importancia de Bogotá en términos de la producción manufacturera.

La producción industrial de Bogotá con respecto a Bogotá-Región ha mantenido su participación alrededor del $80 \%$, pero con una leve tendencia decreciente durante la década de los años noventa. En efecto, la participación de la producción industrial de Bogotá con respecto a la región pasó del $83,8 \%$ en 1990 al 77,2\% en el 2001. Por su parte, la participación de la prestación de servicios de Bogotá, con respecto a la región, presentó una tendencia creciente, hasta superar un $15,96 \%$ en servicios inmobiliarios y alquiler de vivienda y un $10,66 \%$ en servicios bancarios. Según el estudio, dicha tendencia decrece durante los últimos cuatro años, situándose en un $42,5 \%$ en el 2000 , y en un $37,3 \%$ en el 2001 (1,6 puntos porcentuales por debajo de su participación en 1990). En relación con el desarrollo dinámico por su centralidad administrativa y económica, la ciudad aporta a nivel nacional cerca del 30\% del valor agregado en sectores de la construcción y otros servicios y un $25 \%$ en el sector de la industria manufacturera.

3 Caso particular de la ciudad, cuya gran área urbana y sus áreas conexas conforman áreas metropolitanas, como regiones urbanas (Corona, 2004) y que pese a ello su epicentro sigue siendo un comercio matizado por las conexiones de borde y de perímetro. // Entendida como aquel espacio regional que en una economía abierta trasnacional se dispone como un nodo epicentral de desarrollo.

90 Jorge Alessandri Romero Novoa 
Todas estas cifras presentan una ciudad que transita de la industria no consolidada al comercio abierto y los servicios personales o empresariales en crecimiento, características esenciales en la última década del siglo xx.

\subsection{Bogotá: una ciudad transformada en plataforma de servicios (2000-2010)}

En el nuevo milenio, la economía de Bogotá está liderada, principalmente, por la prestación de servicios; le sigue el comercio y, finalmente, la industria manufacturera (Figura 2). E1 comportamiento es similar al nacional, es decir, un crecimiento sostenido desde 2001 y variaciones positivas desde un 2,5\% en el 2001 hasta un 7,3\% en el 2006 (Informe de Coyuntura Económica
Regional, Bogotá y Cundinamarca ICER, 2007). Para este mismo año, el crecimiento real del PIB fue del 3,3\%, con una participación que se mantiene en los últimos años cercana al $23 \%$ del PIB nacional, que en comparación con la década de los años noventa $(20,6 \%)$ mantiene ubicada a la capital como la primera economía del país.

Otras cifras muestran una ciudad industrial que se resiste al cambio de sector económico, con un crecimiento de $4,23 \%$ y una participación nacional promedio del 17\% en el 2003 (ICER, II2003). En el 2004 se manufacturó en Bogotá un $22,7 \%$ de la producción industrial del país, notorio incremento, y aunque llama la atención, no neutraliza la participación en el aumento del

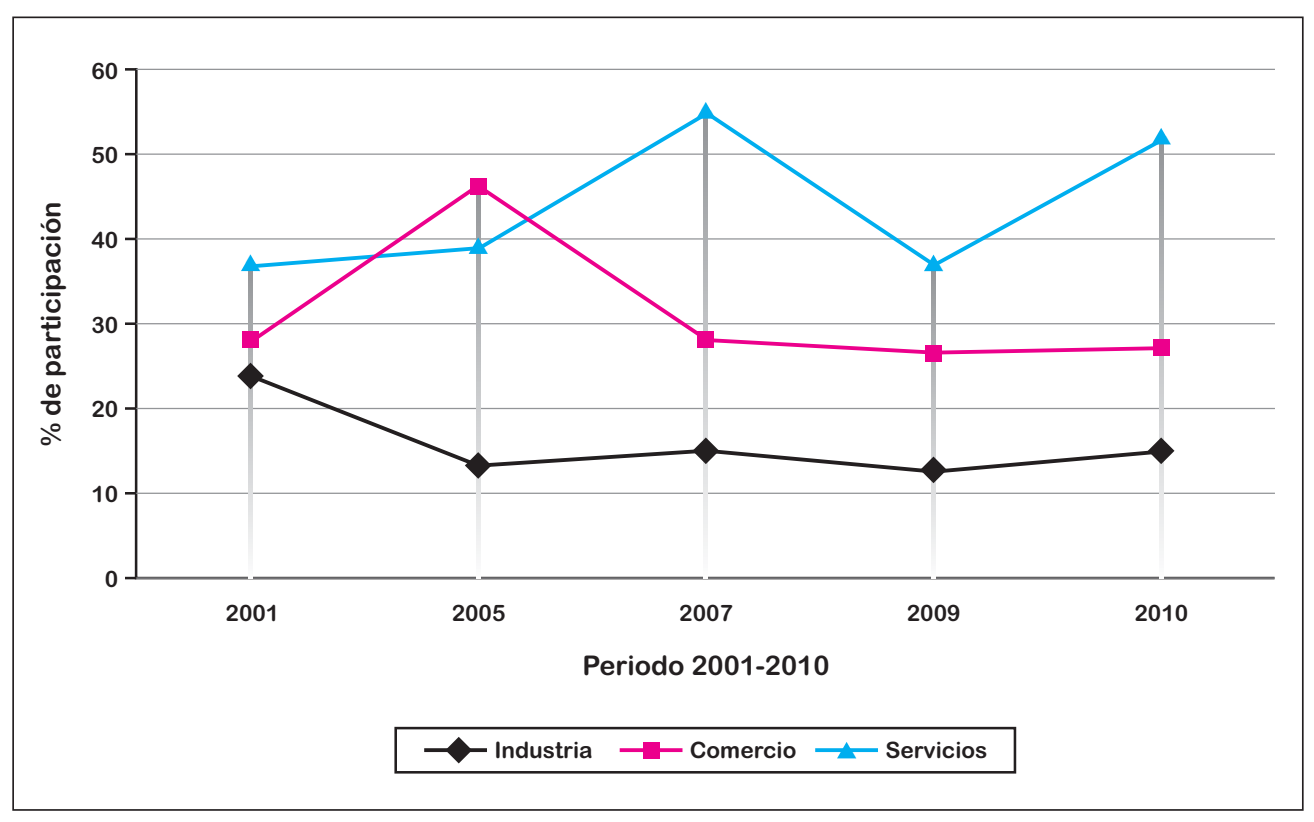

Figura 2. Cambios en el PIB por sectores de Bogotá. 2001-2010

Fuente: elaboración propia a partir de cifras de la SDH. 2010. 
comercio y los servicios, con un $23 \%$ y $27 \%$, respectivamente (ICER, I-2004).

Para el año 2004 existía un incremento en el PIB de la ciudad cercano al $6 \%$ a favor del comercio, en comparación con el de la industria; este crecimiento, continuo desde el 2002, logra ofrecerle a la capital la opción de especializarse en un comercio cualificado de bienes y servicios, principalmente financieros, de conocimiento e intercambio de productos manufacturados. Al cierre del año 2004 la industria cae de un $5 \%$ a un $4 \%$, aproximadamente, en su participación en el PIB.

En el periodo 2003-2006 se presenta la variación más importante en el crecimiento del PIB, con 10,3\% anual, que representa el 25,3\% del PIB comercial nacional, y en el 2009, quizás la caída más fuerte, al $0,1 \%$ del total nacional. La ciudad fortalece su papel como el principal centro de servicios de Colombia, pues en su suelo urbano convergen la mayoría de inversiones provenientes de las demás ciudades del país y de otros lugares del mundo (Secretaría Distrital de Planeación, 2006), consolidándose como un foco dependiente de recursos internacionales y de su gran población nacional.

\section{Población y crecimiento urbano. Cambios continuos en la ciudad}

La incidencia que la liberalización del comercio implanta en Bogotá también es entendida desde la dinámica que han tenido las variaciones en las cantidades de población desde comienzos del siglo xx en el suelo urbano. En los años setenta, el emplazamiento de poblaciones campesinas en suelo periurbano, provocado por problemas de orden público, la consolidación de las guerrillas, la lucha frontal entre partidos políticos, las presiones políticas sobre la población rural, el fortalecimiento de la industria en escenarios urbanos y el aumento de la movilidad demográfica, entre otros, fueron aspectos determinantes que provocaron el aumento acelerado de la concentración poblacional en la ciudad y que las poblaciones rurales habitaran el suelo urbano de la ciudad.

En los años ochenta la ciudad experimentó un crecimiento urbano ahora coincidente con el de sus actividades económicas; la conducta comercial y de servicios sobre el plano urbano le exigen y presionan en dos direcciones: redensificación y expansión urbana; esta década se tradujo en similares comportamientos poblacionales y superficiales de Bogotá.

La Bogotá que se asomaba en los años noventa ganaba cerca de 1.000 .000 de habitantes en una superficie que, a la vez, perdía un $37,40 \%$ de áreas libres; el crecimiento de Bogotá se direcciona hacia el norte, occidente y sur, siendo estas las principales incorporaciones de suelo urbano después de la Ley 388 de 1997.

Con los fenómenos migratorios mencionados y los cambios en las actividades económicas sobre suelo urbano, se conformaron localidades con menor o mayor grado de crecimiento

92 Jorge Alessandri Romero Novoa 
poblacional, localizadas en el centro de la ciudad o en su borde de expansión; como es el caso de La Candelaria, que con 20.993 habitantes $^{4}$ y una superficie de 82,55 ha tiene una densidad habitacional de 254,30 habitantes por hectárea; mientras que Suba, con 1.243.313 habitantes ${ }^{5}$ y una superficie de 6.271 ha tiene una densidad de 198,26 habitantes por hectárea. Densidades que permiten comprender la forma de ocupación del suelo urbano.

Por ejemplo, tomando como referencia los datos de la densidad poblacional, se tiene en el año 1999 un valor máximo de 210 habitantes por hectárea, el cual cae a 159,60 habitantes por hectárea en el año 2000 y se incrementa nuevamente a 191 habitantes por hectárea en el 2010; un fenómeno considerado como tercer ciclo de compactación urbana ${ }^{6}$ (Pérez, 1999) (Tabla 1).

Los datos consignados en la Tabla 1, que se relacionan directamente con la dinámica de áreas urbanas y tamaños poblacionales -consecuencia directa de los cambios económicos que se sucedían en la ciudad-, están acompañados por otros de tipo político, jurídico y sociocultural que complementan la realidad de las dinámicas descritas. Estos son:

De tipo político: la autonomía lograda por los municipios y las ciudades con la elección popular de alcaldes y gobernadores, a partir de 1986.

Tabla 1. Datos urbanos de Bogotá. 1985-2010

\begin{tabular}{|c|c|c|c|c|c|c|}
\hline Año & $\begin{array}{c}\text { Población } \\
\text { (Hab) }\end{array}$ & $\begin{array}{c}\text { Variación } \\
\%\end{array}$ & $\begin{array}{l}\text { Superficie } \\
\text { (Ha) }\end{array}$ & $\begin{array}{c}\text { Pob. Nal. } \\
(\%)\end{array}$ & $\begin{array}{c}\text { Densidad poblacional } \\
\text { (Hab/Ha) }\end{array}$ & $\begin{array}{c}\text { Árealibre } \\
(\mathrm{Ha})\end{array}$ \\
\hline 1985 & 3.982 .941 & - & 24.046 & 14.3 & 165.5 & 17.561 \\
\hline 1993 & 4.945 .458 & 24.16 & 28.721 & 14.9 & 169.86 & 10.992 \\
\hline 1999 & 6.322 .702 & 27.85 & 36.232 & 15.2 & 210 & 8.957 \\
\hline 2000 & 6.422 .198 & 1.57 & 36.232 & 15.27 & 159.6 & 7.972 \\
\hline 2005 & 6.778 .691 & 7.21 & 38.430 & 16.3 & 176.4 & 4.030 \\
\hline 2010 & 7.363.782 & 8.63 & 38.430 & 16.37 & 191 & 2.587 \\
\hline
\end{tabular}

Fuente: elaboración propia a partir de cifras DANE 1973, 1985, 1993 y $2005^{7}$

\footnotetext{
Proyecciones poblaciones realizadas por el autor a partir de las cifras del DANE, censos 1985, 1993 y 2005.

Ibídem.

6 Este suceso es consecuencia de la expansión tentacular y desordenada de la ciudad en la primera década del siglo XXI, en la cual se produce un nuevo impulso a las migraciones periféricas, una nueva dispersión física y socioespacial producto de la política comercial de los años noventa y una nueva disposición normativa sujeta al Plan de Ordenamiento Territorial (POT) desde el año 2000 y ajustada en el 2004 (Decreto 190); con lo que las localidades transformaron sus estructuras espaciales poblacional, infraestructural y comercialmente.

7 http://www.redbogota.com/endatos/0100/0140/01411.htm (marzo 17 de 2010, 10:00am) // Boletín 23. Población y Desarrollo Urbano. Alcaldía Mayor de Bogotá. Secretaría Distrital de Planeación. Bogotá. 2010.
} 
De tipo jurídico: la promulgación de la Ley 9 del 1989, "Ley de Reforma Urbana”, y de la nueva Constitución Política de Colombia, que dotan de más elementos sobre el manejo del territorio y el suelo nacional. Así como de la Ley 136 de 1994, que designó al alcalde como ejecutor de la autoridad política en razón del origen de su elección; de la Ley 99 de 1993, mediante la cual se reorganiza el Sistema de Información Ambiental, y se busca que el desarrollo y crecimiento de las ciudades redunde con una perspectiva sostenible; de la Ley 152 de 1994, por la cual se estable la Ley Orgánica del Plan de Desarrollo, se ordenan las competencias y se consolida el manejo planificado del territorio, y de la Ley 388 de 1997, "Ley de Desarrollo Territorial", con la cual se sentaron los lineamientos, conceptos, mecanismos e instrumentos para regular la ocupación del suelo y el ordenamiento del territorio.

De tipo sociocultural: las diferentes consecuencias de la evolución del narcotráfico y el conflicto armado desencadenan desde 1985 hasta nuestros días elevadas cifras de personas desplazadas, que han llegado aproximadamente a los cuatro millones ${ }^{8}$.

Los cambios descritos permiten marcar con letras sobre la Figura 3 las localidades en las que, en los últimos años, han sido situadas esas migraciones que aceleraron el crecimiento de las poblaciones (en un $25 \%$, para el 2005) y, por ende, la presión edificatoria sobre el suelo (cerca del $95 \%$ se encuentra saturado), disminuyendo la disponibilidad de áreas libres (aproximadamente a un 6,73\%).

A. Usaquén-Suba: redensificación con poblaciones del centro de la ciudad. Facilidad de acceso vehicular. Centralidad urbana del norte.

B. Suba-Engativá: expansión urbana por usos industriales, comerciales y mixtos. Área conexa con los municipios de Funza, Mosquera y Cota.

C. Teusaquillo-Santafé-Candelaria: Centro financiero, administrativo e institucional. Actualmente redensificado.

D. Antonio Nariño-Tunjuelito-Rafael Uribe-San Cristóbal-Ciudad BolívarUsme: expansión urbana por migraciones y desplazamientos rurales al área urbana. Periferia urbana.

E. Ciudad Bolívar-Bosa-Kennedy: expansión y redensificación urbana. Fenómenos de conurbación y espacios periurbanos.

Con todo lo anterior se configura, entonces, un plano urbano dinámico, radialmente hacia afuera y polarizado hacia el norte y el suroccidente; con espacios construidos y soporte de economías locales que inciden en la parcelación, urbanización y edificación desordenada desde 1970 y hasta la fecha. Las localidades presentan dinámicas propias que modifican la combinación de

8 http://www.prensarural.org/spip/spip.php?article1285 (octubre 30 de 2010, 10:30 pm)

94 Jorge Alessandri Romero Novoa 


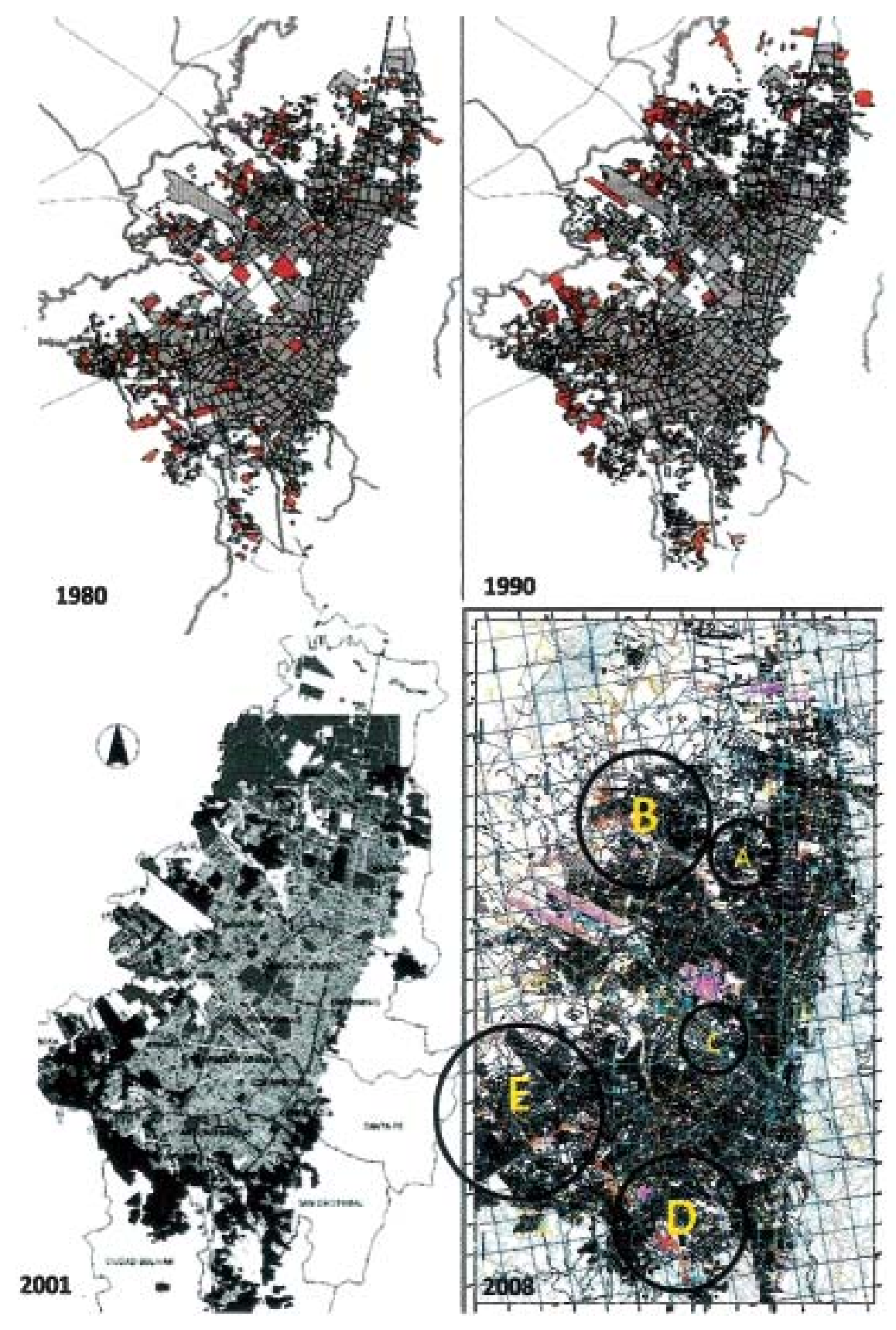

Figura 3. Crecimiento del plano urbano de Bogotá 1980-2010

Fuente: elaboración propia a partir de Red Bogotá-Secretaría de Hacienda Pública (1998); Secretaria de planeación (2006); BiblioCAD-Buitrago, Ginna (2008). 
espacios construidos y libres en el plano urbano, contienen cambios en usos del suelo y fenómenos de concentración poblacional en las últimas décadas, estableciendo un cinturón perimetral de norte a sur por el borde occidental.

\section{Usos del suelo: desindus- trialización y sustitución comercial}

Bogotá ha cambiado las actividades económicas después de la llegada de políticas comerciales y aperturistas en el marco del libre mercado y afines al proceso de globalización, y se ha desindustrializado, siguiendo la tendencia nacional, con una declinante actividad manufacturera, situación que ha incidido en el crecimiento del PIB per cápita de la ciudad (Moncayo, 2008). Este cambio se refleja en las variaciones más sobresalientes de los sectores en la primera década de los años noventa, mencionadas en el aparte anterior.

En la Figura 4 se aprecia la rápida renovación de los usos del suelo urbano; durante los años ochenta y noventa la industria se retrae sobre la calle 26 , dándole paso al uso mixto, residencial con actividades económicas, y comercial predominantemente. Las vías son el principal elemento estructurante sobre el que predominan las actividades comerciales y de prestación de servicios, llegando a una etapa máxima de aparición en la primera década del siglo XXI. Las empresas industriales se asientan en el entorno periurbano (Engativá), y las de servicios técnicos o tecnológicos se dispersan en el interior de las localidades.
Un nodo administrativo y de servicios se concentra (reduce) en las localidades de Candelaria y Santa Fe; esta última puede albergar más de dos millones de habitantes en el día, y solo algo más de 600.000 residentes en la noche (Alcaldía Local de Santa Fe, 2006), con epicentro en la calle 19 y carrera $7^{\mathrm{a}}$. Un nuevo epicentro empresarial y de servicios financieros se implantó en la calle 72 con carrera $7^{\mathrm{a}}$, donde se realizan grandes movimientos de capital nacional e internacional. Entre carreras $7^{\mathrm{a}}, 13, \mathrm{Av}$. Caracas, 24, 30 (NQS) y calles 32,45 , 53,63 y 68 se configura un gran nodo de desarrollo comercial y de servicios, emplazado desde los años ochenta y fortalecido en los años noventa con la introducción de servicios técnicos, tecnológicos y empresariales, hacia el occidente del sector definido y con comercio mixto hacia el oriente.

El comercio local se dispersa en el interior de las zonas residenciales sobre todo el plano urbano, concentrándose longitudinalmente sobre las vías articulantes de las localidades; las Unidades de Planeación Zonal (UPZ) han imprimido un orden planificado en el suelo; sin embargo, la movilidad y flujos de mercancías, la necesidad de empleo, la marginalidad de los espacios públicos y la fragmentación socioeconómica han desdibujado la realidad de los usos del suelo.

En la Figura 4 también se puede observar la concentración del uso comercial (A) y su disposición estratégica, con un conjunto de corredores comerciales sobre los ejes viales longitudinales de la capital (A), en

96 Jorge Alessandri Romero Novoa 


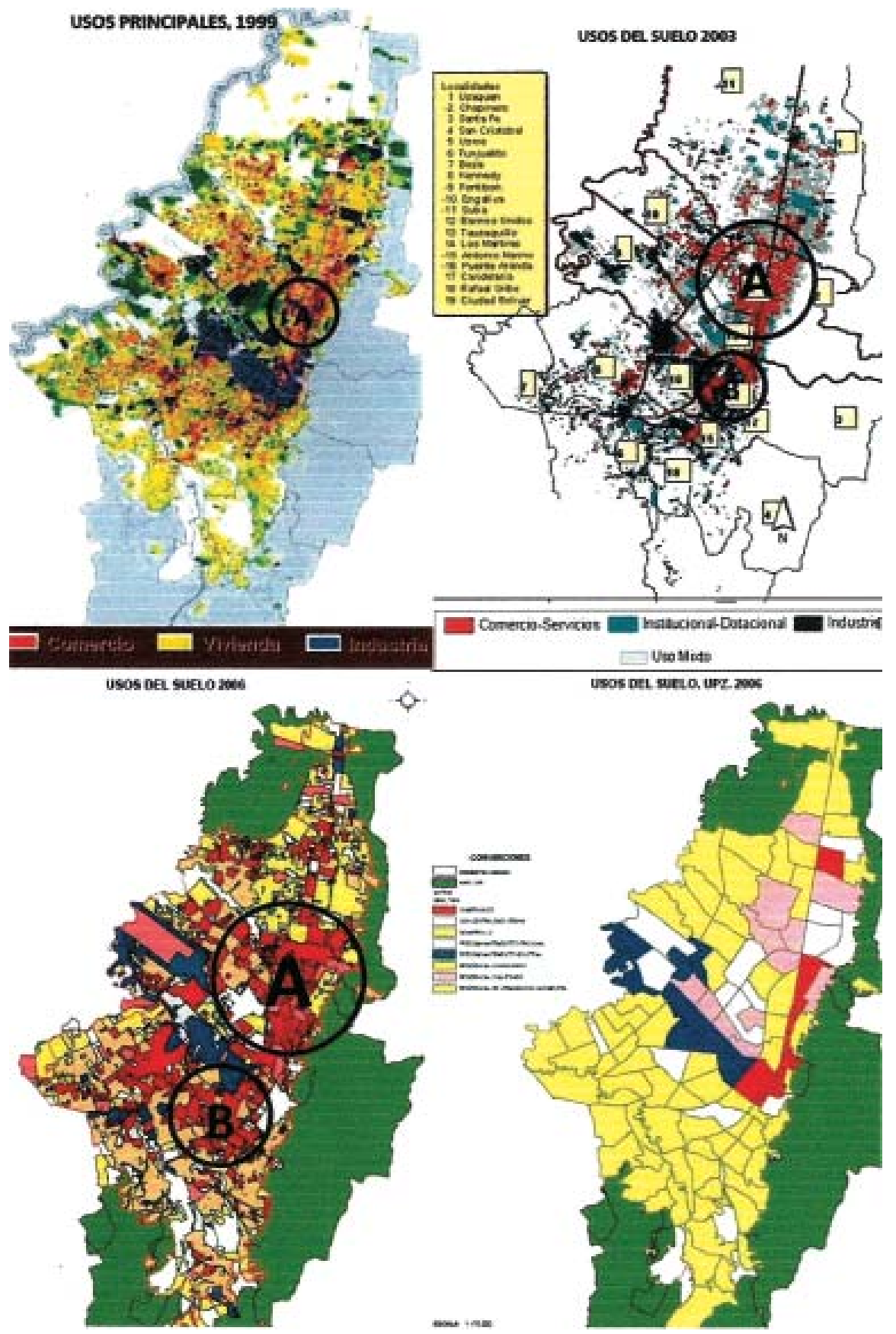

Figura 4. Cambios de los usos del suelo durante los años 1999 a 2006

Fuente: Elaboración propia a partir de las Memorias del Diplomado en Instrumentos de Gestión Urbana. UPTC - IGAC. 2002. Cartografía de la Secretaría de Planeación Distrital (SDP) 2006. 
donde desplaza usos residenciales hacia el norte y occidente de la ciudad. La persistencia del eje transversal sobre la calle 26 sustituye paulatinamente la industria de los años ochenta, enviándola hacia el occidente de las localidades de Fontibón y Engativá, por actividades comerciales y de servicios empresariales $\mathrm{y}$ financieros (B).

La comparación de los tres momentos, 1999 , 2003 y 2006, permite identificar los lugares con mayor concentración de comercio y servicios, además de la relativa dispersión del uso industrial y su relocalización hacia el extremo occidental de la ciudad. El paralelo con el mapa de las UPZ permite evidenciar la cultura informal de los usos comerciales y de servicios empresariales que se vive en las localidades, pues el uso residencial con actividad económica y con servicios se extiende sobre todo el plano urbano de la ciudad.

Es importante comentar que pese a la caída de la industria en la economía de la ciudad, hubo subsectores que, dentro de ella, no sufrieron el mismo evento. Así, se tiene que la pequeña industria tuvo una dinámica positiva de crecimiento, con $107,29 \%$ (Amaya, 1999); la mediana y gran industria presentaron comportamientos positivos y, a la vez, algunos decaimientos notables.

La desindustrialización es lenta; se mantiene sobre las localidades de Puente Aranda, Kennedy, Fontibón y Engativá, siendo estas últimas la que se convierten en el canal de relocalización de la industria (color azul) sobre el perímetro urbano. De otra parte, la aparición de empresas de servicios comerciales e industriales se implanta sobre las avenidas principales de las localidades descritas, buscando la conexión entre el centro y la periferia. Este proceso no ha sido fulminante, pero sí determinante para la conversión económica en la producción de la ciudad. Es importante destacar que la desindustrialización ha sido propiciada, junto con la terciarización de la economía, por la normatividad urbana, los procesos de conurbación convergentes en la metropolización y el crecimiento urbano.

En la década de 1990 a 2000, la pequeña y mediana empresa (sector de servicios comerciales, empresariales o industriales) experimentó el mayor incremento de este rango empresarial (Ramírez, 2006), lo que evidenció el cambio relativo de actividades productivas de la ciudad, incidiendo directamente en el comportamiento del empleo y su distribución espacial. En este punto, la ilegalidad juega un papel importante al distorsionar y aumentar la rugosidad urbanística de Bogotá, puesto que la localización de las actividades no sigue las normas ni postulados urbanísticos, rompiendo con espacialidades económicas lógicas en la siguiente década (comienzos del siglo XXI).

Las empresas, normalmente agrupadas, configuran aglomeraciones en algunas áreas centrales tradicionales (Puente Aranda, Santa Fe, Teusaquillo) y se dispersan por ejes viales principales para la puesta de sus canales de comercialización (Cr. $7^{\text {a }}$, Av. Caracas,

98 Jorge Alessandri Romero Novoa 
Cr. 30, Av. Ciudad de Cali; Calle 19, Calle 45, Calle 53; Calle 63, Calle 72, Calle 100, Calle 116, entre otras); además, facilitan la desconcentración mediante un crecimiento propio y de mayor rango que el entorno residencial donde normalmente reposan (Barrios Unidos, Engativá, Santa Fe). Para la década 20002010 su crecimiento se da sobre actividades preexistentes en usos residenciales, comerciales e industriales, conformando una dinámica disipada en cada localidad.

Así, los cambios económicos y urbanos de la ciudad se replican en los municipios aledaños, que a pesar de su tamaño empiezan a tener dinámicas similares a las de la capital; tal es el caso de municipios como Soacha, al suroccidente; Facatativá, Madrid, Mosquera y Funza, al occidente, y Chía y Cajicá, al norte, cuyas poblaciones subsisten aferradas a su interacción con la comunidad central, ya sean como ciudad dormitorio, ciudad despensa de alimentos, ciudad de industria satélite o ciudad para el turismo del fin de semana de los bogotanos.

\section{Dinámica y transformación urbana de la ciudad}

Los fenómenos urbanos que se definen como efectos espaciales (Figura 5) son generados a partir de la evolución económica y urbana de Bogotá; los escenarios políticos, económicos, comerciales, sociales, ambientales, etc., sucedidos en las dos últimas décadas, generan cambios en la naturaleza de la ciudad y en los sistemas urbanos que la componen (Montoya, 2004).

De partida se hace referencia a la expansión urbana como un fenómeno preexistente y duradero en la configuración urbana de Bogotá; enseguida aparecen dos grandes procesos que prueban la 'elasticidad urbana' de la ciudad: la fragmentación y redensificación urbana, puesto que representan polígonos independientes que se desarrollan con relativa autonomía hacia adentro y hacia afuera (con concentraciones o dispersiones), cargados de servicios empresariales, industriales, constructivos, comerciales, etc. Posteriormente, la aparición de espacios glocales en la ciudad define su economía y su capacidad de participar en el mercado mundial desde mediados de los años noventa y, con mayor fuerza, en los inicios del nuevo milenio, con actividades comerciales y de servicios. Finalmente, y no menos importante, surge un nuevo espacio que se mimetiza en el interior económico de la ciudad, el espacio incontinenti, que podría explicarse como aquel en donde se crea el comercio informal, ilegal y unipersonal. La distribución de estos fenómenos espaciales le da forma a la ciudad y permite su evolución, puesta de manifiesto sobre el plano urbano?.

9 Este es un producto geométrico -que como ya se explicó en el apartado II, es el resultado de la combinación sobre el espacio de la ciudad, de superficies libres (calles, parques y jardines, plazas, lugares de aparcamiento etc.) y también de las superficies construidas- del trazado vial, contenedor de las formas básicas urbanas, como lo son las manzanas, sobre el cual la relación directa, continua y fluctuante, de superficies construidas y espacios no edificados o públicos (Estébanez, 1995). 
El plano implantado densamente sobre el medio físico presenta algunos rasgos esenciales: una dinámica poblacional sucedida en los últimos 50 años (19602010), que todavía presiona el crecimiento, la redensificación y la expansión del suelo urbano; una localización de asentamientos humanos que extienden la infraestructura urbana periféricamente hacia el occidente y el sur; una herencia colonial de trazados urbanísticos que se reduce en un centro histórico más pequeño que el centro financiero; unas actividades productivas dependientes del comercio y los servicios, entre otros.

La red (Figura 5) representa la forma como se concatenan los cambios surgidos sobre el suelo urbano en las últimas décadas, bordeando el hemisferio occidental de la ciudad. La expansión marcada sobre el plano urbano de la capital se direcciona en tres grandes direcciones: Noroccidente, localidad de Suba, con proyectos de urbanización reciente, centralidades administrativas, grandes centros comerciales y desconcentración comercial. Occidente, localidades de Engativá, con relocalización industrial, servicios empresariales y comercio disperso; Fontibón, nuevos proyectos urbanísticos, comercio disperso, servicios empresariales e industriales; Kennedy, nuevos proyectos urbanísticos, comercio concentrado e informal. Y suroccidente, con vivienda social masiva, comercio concentrado, concentración de poblaciones migratorias y desplazadas, y fragmentación socioeconómica.

\section{Expansión urbana}

Un trazado inicialmente cuadrangular, con manzanas tradicionales en el centro (La Candelaria), se sucede por otro rectangular, con variantes de manzanas tradicionales y fragmento de retículas que se transforma en prebarras (ColcienciasCEDE, 1999) de medidas irregulares no parametrizadas, y que no obedecen a ningún diseño preliminar, sino que son producto de barrios ilegales heredados en el último medio siglo, configurando circuitos urbanos de funcionalidad variable en las últimas décadas, hacia su borde perimetral urbano-rural.

Pese al crecimiento exponencial de la población capitalina, el comportamiento demográfico de cada localidad varía, no todas mantienen el ritmo de la ciudad; localidades como la Candelaria, los Mártires, Santa Fe y Puente Aranda decrecen en un $10 \%$; ello se atribuye a la localización relativa de los centros o nodos comerciales principales y sus centralidades en las áreas occidentales de expansión urbana, donde se pueden redensificar proyectos de urbanización. Mientras en localidades como Ciudad Bolívar, Bosa, Kennedy, Engativá y Suba crecen aproximadamente en un 35\%, entre 1985 y 1993, con un decremento del 7\% hasta el 2005.

Llama la atención el cinturón perimetral que aparece por el occidente y en dirección sur-norte, configurando un corredor que se expande hacia el suroccidente y noroccidente de la capital. Allí la localización de nuevos barrios, 


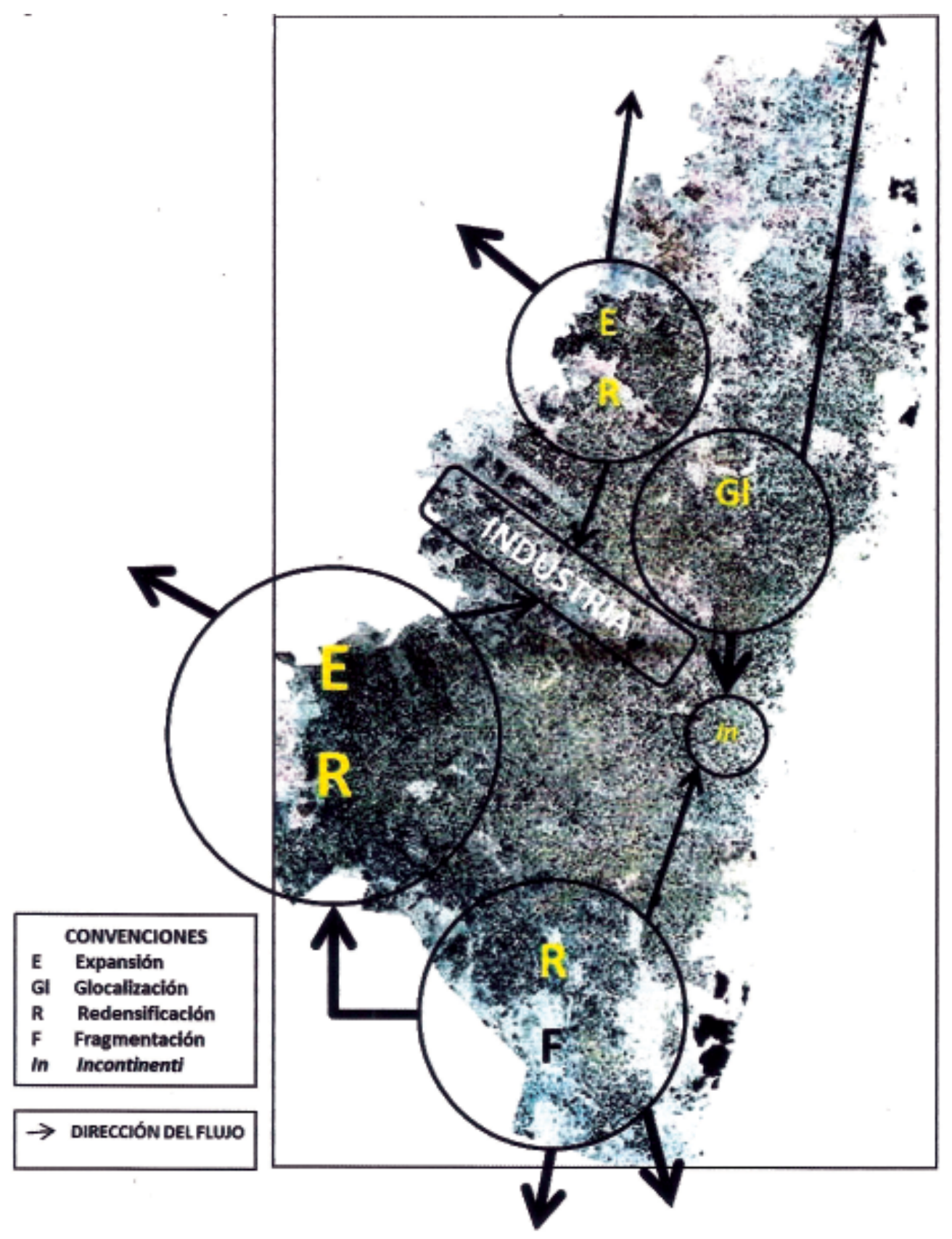

Figura 5. Red de áreas principales de transformación urbana y sus efectos espaciales Fuente: elaboración propia. 
de nuevas zonas residenciales con corredores comerciales que transforman el espacio local urbano, se suma a la construcción de áreas prediales dispersas o predio a predio en barrios con tipología en racimo (Colciencias-CEDE, 1999). La edificabilidad fragmentada y dispersa, que luego fue articulada por la disposición de elementos dotacionales y administrativos, se implanta hacia el sur y suroccidente de la ciudad, con nuevos espacios periurbanos ubicados sobre el municipio de Soacha.

Por el contrario, en localidades del centro histórico (Candelaria y Santa Fe) y su entorno republicano (Teusaquillo, Mártires, Antonio Nariño y Chapinero) han disminuido su tamaño las poblaciones, a la vez que han especializado su suelo en actividades institucionales, comerciales y financieras, expulsando la actividad residencial que originalmente existía.

Sumado a lo anterior, los grupos socioeconómicos de altos ingresos no se relocalizaron en zonas periféricas o suburbanas, sino que hubo alguna dispersión en el interior de cada localidad impulsada por los ejes viales de la Carrera Séptima, de la Avenida Calle 80 y de la Autopista Norte. Consecuente con esto, se conformó una tipología de actividad terciaria a lo largo del eje vial (Cr. 10 ${ }^{\mathrm{a}}$, Cr. $7^{\mathrm{a}}$, Av. Caracas, Autopista Norte) que radia del centro hacia el norte de la ciudad ${ }^{\mathbf{1 0}}$.
Las formas urbanas de la ciudad de Bogotá se definen, entonces, a partir de las transformaciones mencionadas en los párrafos anteriores, que imponen un trazado vial radialmente hacia afuera, cargado de nodos comerciales y administrativos identificados en la capital (La Candelaria, Calle 19 y Cr. $7^{\text {a }}$, Calle 72 y Cr. $7^{\mathrm{a}}$, el CAN, entre los más sobresalientes) y promueven las actividades económicas de cada localidad.

Así, las zonas económicas en cada localidad se disponen a partir de un eje transversal de oriente a occidente que concentra las actividades macro y microeconómicas de la capital sobre la calle 26; de esta hacia el norte se implantan actividades de servicios financieros y empresariales, algunas actividades residenciales, servicios de construcción y grandes superficies; hacia el sur y de forma similar, la actividad constructora reina, sin embargo, la demanda es de un comercio local y puntual, configurando localidades con una periferia urbana rodeada de espacios periurbanos conformados por poblaciones migratorias de las últimas dos décadas. En estas condiciones, las actividades productivas se aglomeran en el sector terciario de comercio y servicios, con un porcentaje que alcanza y supera en algunas localidades el 50\% de establecimientos dedicados a dicha actividad (DANE, 2005).

10 Estudio denominado "Estructura y tendencia de crecimiento" (Molina, 1992).

102 Jorge Alessandri Romero Novoa 
Redensificación y fragmentación urbana

El incremento de la población por procesos migratorios de diferente índole (desplazamiento forzoso, desplazamiento por necesidades académicas y de salud, desplazamiento laboral, ciudad dormitorio, etc.) desencadenó la sobreutilización del suelo urbano, y en este, la aparición de zonas redensificadas que promueven la re-localización residencial periférica.

Con una saturación proyectada del $95 \%$ y un déficit de 280.000 viviendas, la ciudad explora la posibilidad de extender su espacio urbano al suelo municipal conexo (Estadísticas Gobierno Distrital, 1999-2010). Cerca del 53,87\% del área total desarrollada concentra las actividades residencial y económica, las cuales están en permanente cambio. La ocupación del suelo urbano en las localidades se concentra en el uso residencial exclusivo y en el comercial exclusivo, con una relación que duplica el primero frente al segundo; estos son los mayores desarrollos urbanísticos de los últimos años.

Las manifestaciones que se dan sobre las localidades en relación con el aumento de áreas construidas, la densificación del área urbanizada, el aumento en el número de edificaciones, la disminución de áreas libres, etc., se configuran como reacción a la escasez de suelo urbano en la presente década. Las estrategias más utilizadas por el Distrito han sido, por un lado, la de asociar áreas urbanas de municipios vecinos e históricamente partícipes de la metropolización urbana, con un cambio en el perímetro de la ciudad (expansión urbana), y por el otro, la de mirar hacia dentro de su suelo urbano buscando áreas urbanizables no urbanizadas, predios baldíos y zonas de desarrollo urbanístico (redensificación urbana). Estas estrategias han generado que la ciudad recomponga su suelo urbano en dos sectores: uno con impacto global, que se redensifica, normalmente, hacia el centro urbano, y otro con incidencia local, que se fragmenta, normalmente, hacia el borde urbano-rural.

Con base en lo anterior, la ciudad se divide en dos zonas: las localidades del centro urbano y las de borde, con injerencia en el perímetro urbano; las primeras son Barrios Unidos, Teusaquillo, Puente Aranda, Los Mártires y el sector oriental de Fontibón y de Engativá, caracterizadas por contener las actividades comerciales y de servicios financieros o empresariales que hacen parte de las exportaciones de productos e importaciones de materia prima; las segundas son Suba, el sector occidental de Engativá y de Fontibón, Kennedy, Bosa, Tunjuelito, Ciudad Bolívar y Usme, caracterizadas por contener las últimas migraciones de familias y grupos de poblaciones vecinas, con usos comerciales dispersos, puntuales o de corredor; con uso residencial predominante y consolidado y con una tipología de edificación heterogénea.

Por otro lado, la fragmentación ha sido desde siempre estimulada por fenómenos como la dispersión de la ciudad, la 
conurbación urbana y el policentrismo (DAPD, Alba et al., 2002). El primero, propiciado por la localización dispersa de las actividades económicas, tanto industriales, agroindustriales y extractivas, sobre el borde urbano-rural contiguo a los principales ejes de comunicación regional de Bogotá; de igual manera, la escasez de suelo urbanizable en Bogotá, con relación a su área ya urbanizada, contrasta con la amplia oferta de suelo de expansión en los municipios de la sabana centro: Facatativá, Madrid, Mosquera, Funza, Cota, Cajicá, Chía, Sopó y la Calera, entre otros. Con relación a sus actuales áreas urbanas, una parte relativamente importante de las proyecciones de crecimiento de la nueva población se deberá localizar por fuera de los límites urbanizables de la ciudad, dados los condicionamientos del Ministerio de Ambiente, Vivienda y Desarrollo Territorial (MAVDT), lo que llevará a dispersar sobre los municipios de la Sabana sus áreas de vivienda y dotaciones complementarias.

El segundo fenómeno, la conurbación urbana, se ha soportado en el crecimiento de la población, en la infraestructura de carreteras que une los distintos centros urbanos de la sabana, en las mejores condiciones del transporte público y en la extensión de la urbanización, con mejores y renovadas condiciones de centralidad. Además, el establecimiento de lugares de segunda residencia, o en algunos casos de residencia principal, en las áreas rurales de los municipios aledaños, se ha caracterizado como una conurbación suburbana soportada por la red de caminos y carreteras veredales.

El tercero cumple dos objetivos primordiales: ser respuesta a la implantación de barrios residenciales sin las debidas dotaciones complementarias a su actividad, y, a la vez, acompañar la descentralización de las actividades productivas (Alba, 1998).

\section{Espacios glocales y espacios incontinenti}

Bogotá es una ciudad con una doble función territorial. Por un lado, es el epicentro económico y estratégico del país para la inversión extranjera, para mercados financieros y recepción de población migratoria; por otro lado, compone el área metropolitana de la sabana e incide en el centro del departamento de Cundinamarca. Con base en esta dualidad: espacio local y global, la ciudad se define en un plano longitudinal que no coincide con su espacialidad urbana; esta sobrepasa los límites administrativos y físicos establecidos en la normatividad.

Al finalizar los años ochenta y durante los años noventa se introdujeron importantes modificaciones en la orientación de la política económica de Colombia y, por extensión, de Bogotá, con consecuencias directas sobre el desarrollo socio-espacial de la ciudad, haciéndola atractiva para la inversión del resto del país y del mundo, incentivando un punto de desarrollo turístico, localizando un comercio tecnológico de punta y estimulando la migración nacional 
de hasta 50 familias por día ${ }^{11}$ (por el desplazamiento forzoso), la aparición de barrios ilegales, la predialización dispersa y la construcción de edificaciones sin planificación alguna.

Según Cuervo y Alfonso (2001), la liberalización del comercio del país no solo promovió el crecimiento de los intercambios con el resto del mundo especialmente las importaciones-, sino que consolidó las funciones de Bogotá como punto de relevo y conexión entre las economías doméstica e internacional. El comercio, como sector económico, recibió un gran impulso, y las inversiones industriales se reactivaron a través de la importación de maquinaria y equipo. La ciudad se convirtió en un gran espacio glocal: 'pensando globalmente y actuando localmente'.

Se desenlaza, entonces, un acelerado crecimiento de la importación y producción (p. ej. de automóviles), se liberalizó el transporte aéreo, se incrementó la competencia a partir de la cual se produjo un acelerado crecimiento de la movilidad nacional e internacional, se liberalizó el sector financiero y aumentaron las inversiones nacionales y extranjeras, creciendo rápidamente el volumen de negocios, el comercio, la industria y el sector de la vivienda y la construcción en general. Todo lo anterior explica el acelerado crecimiento económico de la ciudad y la transformación física y funcional de muchos de sus sectores, zonas y localidades en el interior o en su perímetro urbano.

Así como se dio origen a los aglomerados industriales, a los sectores residenciales, a los corredores comerciales y a las zonas francas, surgen, por otra parte, los espacios individuales y puntuales, espacios incontinenti que no requieren del entorno inmediato para su subsistencia. Estos son producto de la entrada de nuevas tecnologías en los medios de comunicación, en la transmisión de datos e información, y de la creación de espacios virtuales que dinamizan la existencia de los lugares; por ejemplo, el centro histórico de la ciudad, el corredor comercial y de servicios de la calle 26 hacia el aeropuerto, y el centro financiero o de negocios de la Cl. 72; las universidades, como epicentro de un clúster económico, configuran actividades comerciales que se puntualizan y fijan en el interior de este.

El intercambio de mercancías, bienes, productos, servicios e incluso del mismo conocimiento e información se lleva a cabo de forma inmediata; es decir, con la contracción del espacio comercial las velocidades de comunicación entre productores y consumidores es rápida, y se implantan en escenarios puntuales, locales e internos, sin relación con el entorno inmediato, modificando la esencia del lugar; por ejemplo, las áreas de comercio aduanero, como los llamados 'San Andresitos' y los comercios informales sobre espacios públicos o semáforos.

$\overline{11}$ Administración Distrital y Acnur-2009. 
El espacio incontinenti es puntual o nodal, de beneficio propio, definido por individuos y aglomeración de individuos (o si se prefiere, de poblaciones) especializados en actividades comerciales informales que se implantan por doquier, manteniendo el interés por el entorno, pero no por el tamaño ni por el orden de los flujos; aquí los lugares son definidos como sitios de interés, cuyo tamaño pierde importancia, puesto que en un punto, un mínimo punto real o abstracto, se puede llevar a cabo la actividad económica.

\section{Conclusiones}

Para identificar los aportes logrados en el presente texto, las conclusiones se han agrupado en tres tipos: las referidas a los cambios económicos, las que relacionan variaciones poblacionales y uso del suelo, y las que hacen referencia a los fenómenos urbanos que transformaron la ciudad.

Sobre el primer grupo debe indicarse que de la articulación mencionada surgieron elementos poblacionales, económicos y del suelo urbano que dinamizaron la ciudad, como fueron: el aumento en el tamaño de la población, en un 48,90\% acumulado desde los años noventa ${ }^{12}$, en correspondencia con el incremento en la superficie urbana en un $33,80 \%$; la disminución del área urbana libre en un $76,46 \%$ del total asignado a comienzos de los años noventa; la escasez de los espacios urbanizables, saturados al $95 \%$, y el déficit de 280.000 viviendas en suelo urbano; la transición de un sistema proteccionista con una industria incipiente a otro aperturista basado en el comercio y los servicios, cuya participación en el PIB nacional alcanza a ser del $25 \%$ del total nacional, y los crecimientos del $2 \%$ al año de la industria capitalina, que desvirtúan su desaparición, y de 3 o 4\% del sector terciario, que crece más rápido que el secundario.

En el segundo grupo debe señalarse que, por un lado, la ciudad ha entrado en la última década en el tercer ciclo de compactación urbana, puesto que al cerrar el año 1999 y empezar el 2000, las cifras relacionadas con densidades poblacionales entraron en un nuevo punto de partida, estimuladas por la expansión de la ciudad, las migraciones de poblaciones vecinas -debido al desplazamiento forzoso- y el incremento de la población en los bordes urbanos; y por el otro, que el cambio de industria a comercio y la mezcla de usos comerciales y de servicios han estimulado la configuración de corredores comerciales que mantienen flujos constantes de personas, recursos y mercancías no restringidas que se trasladan a espacios periurbanos localizados en el extremo de la ciudad y que conforman el drama de la nueva metropolización. La normatividad administrativa que condiciona o permite ubicar dichas

12 Es importante considerar la disminución de la variación en el crecimiento poblacional entre 1993 y 2005, la cual pasa de un incremento promedio del $24,16 \%$ a un $7,21 \%$. Para el periodo entre 2005 y 2010 hay un leve repunte del $8,63 \%$ en el aumento de la población.

106 Jorge Alessandri Romero Novoa 
actividades no integra mecanismos de manejo y control de los problemas socioculturales y político-económicos que también inciden en la transformación urbana de la ciudad, cuya principal respuesta se produce en el rezago de la industria o en la desindustrialización y el fortalecimiento de nuevos espacios económicos que la sustituyen por actividades comerciales y de servicios, fenómeno aún creciente.

En el tercer y último grupo es importante reconocer que la dinámica urbana de la ciudad ha generado cambios en dos direcciones: hacia su centro tradicional, histórico y financiero (redensificación) $\mathrm{y}$ hacia las localidades que conforman su perímetro urbano (expansión y fragmentación). Los cambios sucedidos en la primera dirección soportaron la concentración urbana en las localidades denominadas aquí de centro, por su localización, sobre las cuales se ha venido conformando el área financiera y comercial de la ciudad; en ellas la redensificación urbana del suelo y la diversificación de los mercados promueven la aparición de actividades comerciales y la oferta de servicios empresariales, reduciendo los usos tradicionalmente residenciales, cuya principal consecuencia es la aparición de una zona intermedia de transición donde se marcan usos mixtos, comercio informal y zonas. En una segunda dirección, hacia afuera, o borde urbano de la ciudad, sobre las localidades perimetrales, cambios marcados principalmente por la fragmentación urbana, dominando tres fenómenos específicos: comercio disperso e informal;conurbación, de dos tipos: ilegal y en zonas de riesgo hacia las estribaciones del sistema paramuno del Sumapaz y hacia Soacha, y de élite, sobre los cerros orientales, con gran anuencia del mercado de capitales inmobiliarios, y, finalmente policentrismo urbano, acompañado de la desconcentración administrativa. De tal manera que las localidades que bordean la ciudad se reconfiguran en receptoras de ambos fenómenos, cargados de la migración de poblaciones, la persistencia del crecimiento poblacional, las dinámicas de construcción que pasan de la legalidad a la ilegalidad, de la formalidad a la informalidad y de la planificación a la espontaneidad, lo que promueve la metropolización en áreas circunvecinas.

La Figura 6 muestra de manera concreta y concluyente los efectos espaciales definidos en el suelo urbano de Bogotá, los cuales transforman la ciudad desde 1990 y hasta la actualidad. 


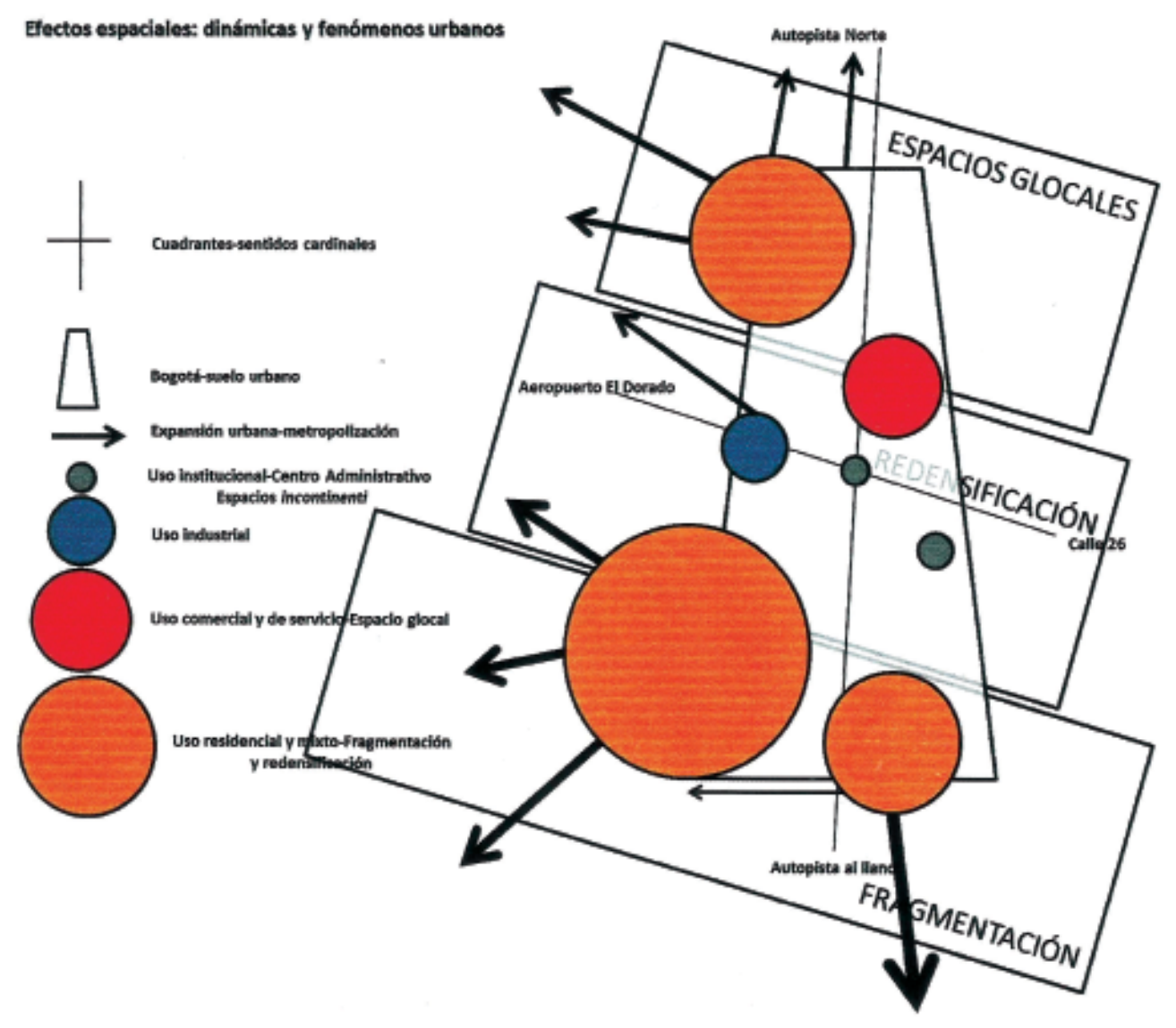

Figura 6. Efectos espaciales: dinámicas y fenómenos urbanos en la ciudad de Bogotá Fuente: elaboración propia. 


\section{Literatura citada}

Alba Castro, J. M. (1998). El surgimiento de las centralidades en las periferias urbanas de Santa Fe de Bogotá. Tesis de Magíster en Urbanismo. Bogotá: Universidad Nacional.

Alba Castro, J. M. et al. (2002). Estudios y recomendaciones para desarrollar la estrategia de competitividad definida en el Plan de Desarrollo 2001-2004. Bogotá: DAPD.

Alcaldía Mayor de Bogotá. (2000). Estadísticas del gobierno distrital. Bogotá: Secretaría de Planeación.

Amaya, P. (1999). Perfil tecnoeconómico de las industrias más dinámicas. Alcaldía Mayor de Bogotá. DAPD. Documento técnico soporte. Bogotá D.C.

Ascher, F. (2001). Les nouveaux principes de l'urbanisme. La Tour d'Aigues: Editions de l'Aube.

Boisier, S. (2005). ¿Hay espacio para el desarrollo local en la globalización? CEPAL, 86.

Borja, J. (2007). Revolución y contrarrevolución en la ciudad global: las expectativas frustradas por la globalización de nuestras ciudades. EURE, 33(100): 35-50. Santiago de Chile.

Bustamante Pérez, L. (2007). Crecimiento urbano y globalización: Transformaciones del Área Metropolitana de Concepción, Chile, 1992-2002. Revista Electrónica de Geografia y Ciencias Sociales. Scripta Nova, vol. XI, n. ${ }^{\circ}$ 251. Universidad de Barcelona.

Cámara de Comercio de Bogotá. (2002). Indicadores sociales de las localidades. Observatorio Social de Bogotá, n. ${ }^{\circ}$ 10. Bogotá D.C.

Cámara de Comercio de Bogotá. (2010). Comportamiento de la economía de la región en el primer semestre de 2010. Observatorio de la región Bogotá-Cundinamarca, n. ${ }^{\circ}$ 9. Bogotá D.C.

Castells, M. y Murphy, K. (1982). Cultural Identity and Urban Structure: the Spatial Organization of San Francisco's Gay Community. Urban Affairs Annual Reviews, 22: $1-20$.

Castells, M. (2000). La ciudad de la nueva economía. La Factoría, n. ${ }^{\circ}$ 12. California: Universidad de Berkeley.

Castells, M. (2004). Crisis y reinvención de la ciudad contemporánea. "Ciudades europeas, la sociedad de la información y la economía global”. Archipiélago. Cuadernos de crítica de la cultura, n. ${ }^{\circ}$ 62. Barcelona.

CEDE. (1996). Desarrollo socio-espacial de Bogotá durante las dos últimas décadas. Una aproximación preliminar a sus principales rasgos. Bogotá: Universidad de los Andes. Mimeo.

Perspect. geogr. Vol. 15. Año 2010, pp. 85-112 109 
CID. (2005). Estudio de las barreras al comercio de bienes y servicios de Bogotá en el contexto de un tratado de libre comercio con Estados Unidos. Producto 1. Definición y priorización de sectores estratégicos en el mercado de Estados Unidos. Bogotá: Centro de Investigaciones para el Desarrollo. Universidad Nacional de Colombia.

COLCIENCIAS-CEDE. (1999). Tendencias recientes de ocupación territorial en Bogotá y la región. Bogotá: Universidad de los Andes. Convenio Gobernación de Cundinamarca.

Corona Rentería, A. (2004). Migración rural y urbana. En las migraciones rurales. Huánuco.

Cuervo González, L. M. (1999). Expansión metropolitana y globalización en Bogotá. Ponencia presentada al $V$ Encuentro de la Red Iberoamericana de Investigadores sobre Globalización y Territorio, Toluca, México. Bogotá: Universidad de los Andes. CIDER.

Cuervo González, L. M. y Alfonso Roa, O. A. (2001). Ciudad y región en Colombia. Nueve ensayos de análisis socioeconómico y espacial. Primera parte: localización de la actividad económica y el empleo. Bogotá: Universidad Externado de Colombia.

Cuervo González, L. M. y González, J. (1997). Industria y ciudades. Bogotá: Tercer Mundo.

DANE. (2003). Informe de coyuntura económica regional de Bogotá - Cundinamarca. Bogotá D.C.

DANE. (2005). Perfil por localidades. Boletín Censo General 2005. Bogotá D.C.

DANE. (2007). Encuesta de Calidad de Vida (ECV). Bogotá D.C.

De Mattos, C. (2002). Transformación de las ciudades latinoamericanas: ¿Impactos de la globalización? EURE, 28(85): 5-10. Santiago. Obtenido de:

$<$ http://www.scielo.cl/scielo.php?script $=$ sci_arttext\&pid $=$ S0250-

$71612002008500001 \& \operatorname{lng}=\mathrm{es} \& \mathrm{nrm}=$ iso $>$

De Mattos, C. (2004). Globalización y urbanización en América Latina. Documento electrónico de The Inter-American Institutefor Global ChangeResearch (IAI). Santiago. Obtenido de: http://www.iai.int/SI/2004/2004UGEC_files/Lectures/Carlos_Mattos.pdf

De Mattos, C. (2007). Globalización, negocios inmobiliarios y transformación urbana. [El artículo es copia fiel del publicado en la revista Nueva Sociedad N. ${ }^{\circ} 212$, noviembre-diciembre de 2007. Santiago. Obtenido de http://www.nuso.org/upload/ articulos/3481_1.pdf.

Duque Franco, I. (2008). Planeamiento urbano en Bogotá 1994-2007. La construcción de un modelo. X Coloquio Internacional de Geocrítica. Diez años de cambios en el mundo, en la Geografía y en las Ciencias Sociales, 1999-2008. Doctoranda en Geografía. Barcelona: Universidad de Barcelona.

I 10 Jorge Alessandri Romero Novoa 
Fernández Parratt, S. (2002). La glocalización de la comunicación. Madrid: Universidad Carlos III.

Font. A. (1997). Anatomía de una metrópoli discontinua: la Barcelona Metropolitana.Papers. Región metropolitana de Barcelona n. ${ }^{\circ}$ 26, pp. 9-19. Obtenido de http:// campus.uab.es/iermb/papers/Papers26/CAP1.pdf

Galvis, L. A. y Meisel Roca, A. (2000). El crecimiento económico de las ciudades colombianas y sus determinantes, 1973-1998. Centro de investigaciones económicas del Caribe colombiano. Banco de la República, n. ${ }^{\circ}$ 18. Cartagena de indias. Bogotá D.C.

Garzón Vivas, H. J. (2004). Aspectos del Tratado de Libre Comercio entre Colombia y Estados Unidos. Su impacto en el sector agrícola, la productividad y el empleo. Universidad Libre de Colombia. Facultad de Contaduría. Gestiopolis. Bogotá D.C.

ICER. (2003). II Informe de coyuntura económica regional, Bogotá y Cundinamarca.

ICER. (2004). I Informe de coyuntura económica regional, Bogotá y Cundinamarca.

ICER. (2007). Informe de coyuntura económica regional, Bogotá y Cundinamarca.

Jiménez Reyes, L. C. (2001). Algunos efectos en la organización del espacio geográfico. Ciclo de conferencias "Colombia y el cambio global"- Geografía del cambio "global". Departamento de Geografía. Universidad Nacional de Colombia. Bogotá D.C.

Londoño, J. L. (2002). Comercio, recursos y desigualdad en América Latina. CEPAL, N. ${ }^{\circ}$ 78. Bogotá D.C.

Massiris Cabeza, Á. (2000). Ordenamiento Territorial y procesos de construcción regional. [Libro en edición virtual sobre el concepto de ordenamiento territorial]. Biblioteca Luis Ángel Arango. Bogotá D.C.

Moncayo Jiménez, E. (2007a). Impactos territoriales de la globalización. Segunda parte: “Transformaciones espaciales". Universidad Autónoma de Colombia. Bogotá D.C.

Moncayo Jiménez, E. (2007b). Dinámicas regionales de la industrialización. Segunda parte: "Las transformaciones espaciales de la economía colombiana". Facultad de Ciencias Administrativas, Económicas y Contables. Universidad Central. Bogotá D.C.

Moncayo Jiménez, E. (2008). Impactos Territoriales de la Globalización. [Presentación en el segundo ciclo de conferencias de la Sociedad Geográfica de Colombia Academia de Ciencias Geográficas: "Martes del Planetario". Colombia: Impacto Económico y Político en el Territorio. Bogotá D.C.

Montoya, J. W. (2004). Sistemas urbanos en América Latina: Globalización y urbanización. Cuadernos de Geografía, 13: 39-58. Departamento de Geografía. Universidad Nacional de Colombia, Bogotá D.C.

Montoya, J. W. (2006). Cambio urbano y evolución discursiva en el análisis de la ciudad latinoamericana: De la dependencia a la globalización. Serie Trabajos en Geografía. Universidad Nacional de Colombia. Bogotá D.C. 
OMC. (2008). El comercio en un mundo en globalización. Organización Mundial del Comercio (OMC).

Pérez Preciado, A. (1999). La expansión de Bogotá. Bogotá : CAR. Obtenido el 8 de enero de 2010 de www.redbogota.com/univerciudad/bajar-pdf/expansionbogota.pdf.

Portes, A. y Roberts, B. (2005). La ciudad bajo el libre mercado: La urbanización en América Latina durante los años del experimento neoliberal. Universidad de Texas en Austin, Universidad de Princeton.

Red Bogotá. (2000). Evolución urbana de Bogotá en ocupación y territorio. Crecimiento urbano. Descripción de la ciudad. Instituto de Estudios Urbanos. Bogotá D.C. Obtenido de http://www.institutodeestudiosurbanos.com/endatos/0100/0140/ 01411.htm

Ramírez Castro, M. M. (2006). Tendencias espaciales de la pequeña y mediana empresa en Bogotá. Universidad Nacional de Colombia. Facultad de Artes. Bogotá D.C.

Rincón Avellaneda, P. (2006). Bogotá y sus modalidades de ocupación del suelo. Análisis de los procesos de re-densificación. Universidad Nacional de Colombia. Bogotá: Punto Aparte.

Roa, O. A. y Rentería Salazar, P. (2002). La ciudad: transformaciones, retos y posibilidades. Bogotá: Centro Editorial Javeriano.

Saldarriaga Roa, A. (2000). Bogotá siglo xx. Urbanismo, arquitectura y vida urbana. Bogotá: Alcaldía Mayor.

Sandoval Castro, C. M. (2002). Diplomado en Instrumentos de Gestión Urbana para el Ordenamiento Territorial. Convenio UPTC-IGAC. Bogotá D.C.

Sassen, S. (2003). Localizando ciudades en circuitos globales. EURE, 29(88): 5-27. Santiago de Chile.

Secretaría Distrital de Planeación. (2006). Información catastral para el proyecto de definición de una red de asentamientos del borde sur de Bogotá. Convenio 017 con la Universidad Distrital Francisco José de Caldas. 2010. Bogotá D.C.

Soja, E. (2001).Urban tensions: globalization, industrial restructuring, and the Postmetropolitan transition.Global Tensions. CornellUniversity. UCLA. Los Ángeles.

UPTC-IGAC. (2002). Memorias del Diplomado en Instrumentos de Gestión Urbana. Bogotá D.C.

Zárate, A. (1992). El mosaico urbano. Organización interna y vida en las ciudades. Madrid: Cincel Kapelusz.

Recepción: 01 de octubre de 2010

Aprobación: 29 de noviembre de 2010

I 12 Jorge Alessandri Romero Novoa 